\title{
Evaluation of Decomposition Kinetics of Poly (Ether-Ether-Ketone) by Thermogravimetric Analysis
}

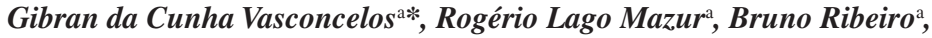 \\ Edson Coccieri Botelho ${ }^{\mathrm{a}}$, Michelle Leali Costa ${ }^{\mathrm{a}, \mathrm{b}}$ \\ ${ }^{a}$ Departamento de Materiais e Tecnologia, Faculdade de Engenharia de Guaratinguetá, \\ Univ Estadual Paulista - UNESP, Guaratinguetá, SP, Brazil \\ ${ }^{\mathrm{b}}$ Divisão de Materiais, Instituto de Aeronáutica e Espaço - IAE, Departamento de Ciência e \\ Tecnologia Aeroespacial - DCTA, São José dos Campos, SP, Brazil
}

Received: March 7, 2013; Revised: November 9, 2013

\begin{abstract}
The non-isothermal thermogravimetric methods have been used extensively for the determination of kinetic parameters in polymers. The poly (ether ketones) are used as matrix in advanced high performance composites due its high thermal stability, excellent environmental performance and superior mechanical properties. In this work, the non-isothermal decomposition kinetics of the polymer poly (ether ether ketone) (PEEK) was evaluated in nitrogen and synthetic air atmospheres, using the Flynn-Wall-Ozawa and Coats Redfern models. The results showed that the necessary time for the material decomposes in 5\% is approximately 216 years if it is submitted to temperatures of $350{ }^{\circ} \mathrm{C}$ in nitrogen atmosphere. On the other hand, if the material is submitted to air atmosphere, this decomposition time drops to about 1,05 years in the same temperature and for the same conversion rate. The decomposition kinetics study by Coats Redfern showed that the D3 mechanism (three-dimensional diffusion (Jander equation)) had better adjustment to the decomposition kinetics of the material in nitrogen atmosphere, while in synthetic air the $\mathrm{R} 1$ mechanism (phase boundary controlled reaction (one-dimensional movement)) has better adjustment to the decomposition kinetics of the material.
\end{abstract}

Keywords: poly (ether ether ketone), degradation kinetic, thermogravimetry

\section{Introduction}

The poly (ether ketones) are used as matrix in advanced high performance composites due its high thermal stability, excellent environmental performance and superior mechanical properties. Some of its derivatives polymers are poly(ether ether ketone) (PEEK), poly(ether ketone) (PEK), poly(ether ketone ether ketone ketone) (PEKEKK), and poly(ether ketone ketone) (PEKK) ${ }^{1}$. PEEK offers excellent chemical resistance and good chemical and physical properties at high temperatures. Recently, they have been widely used in commercial applications, where high temperatures and resistance are required ${ }^{2-4}$.

The main products of PEEK decomposition have been identified as $\mathrm{CO}, \mathrm{CO}_{2}$, phenols and some aromatic ethers 5 . The first stage of ether and ketone thermal cracking produces a great amount of phenol and $\mathrm{CO}_{2} / \mathrm{CO}$. In the subsequent stage, the fluorenone structure appears in part of the carbonization scheme. Hence, the major cracking products are $\mathrm{CO}_{2} / \mathrm{CO}$ from the ketone group of the fluorenone in the carbonization structure previously described. It has been proposed that the decomposition of PEEK occurs through competing mechanisms. These are mainly chain scission, leading to volatile fuel formation, and cross-linking, leading to char formation. PEEK decomposition is initiated by random homolytic scission of either the ether or the carbonyl

*e-mail: gibran_v@hotmail.com bonds in the polymer chain, although there is disagreement as to which of these bonds is more stable. It is believed that as most of the products of PEEK decomposition contain terminal hydroxyl groups and there are few with aldehyde units that the ether links are less thermally stable.

In oxygen presence, the second degradation step of PEEK occurs due to thermo-oxidation. The process is enhanced by lower heating hates, which permits greater diffusion of oxygen through the melt ${ }^{6-9}$.

The thermogravimetric analysis has been widely used as a method for investigate the thermal decomposition of polymers and for determine their thermal stability. Furthermore, a great attention has been given aiming thermogravimetric data extrapolation for obtaining kinetics parameters ${ }^{10}$. Controlled thermal processing of substances can yield important information on the heterogeneity, constitution, structural elements, durability, thermodynamics, metastable or polymorphic states of a compound, physical application, and limitations of a compound $^{11}$.

The kinetic analysis of a decomposing material can be done using two different techniques: the dynamic and the isothermal thermogravimetric studies. The dynamic thermogravimetric data can be analyzed using two different methods, the isoconversional and the discrimination 
methods ${ }^{12}$. The isoconversional methods use the data from a series of thermogravimetric (TGA) curves obtained at different heating rates to calculate the activation energy $\left(\mathrm{E}_{\mathrm{a}}\right)$ but do not provide any information about the kinetic function $(\mathrm{g}(\mathrm{x}))$ of the process. The discrimination methods use the solution of an equation based upon a given model and allow the simultaneous determination of Ea and $\mathrm{g}(\mathrm{x})$. Detailed kinetic analysis on plastics and on poly (ether ether ketone) can be found reported in the literature ${ }^{13-21}$.

The present paper describes a kinetic study of the thermal degradation of poly (ether ether ketone) under dynamic conditions using an isoconversional and discrimination method. In this work the non-isothermal curves generate by thermogravimetry (TGA) are used to study the degradation kinetics of PEEK using the Flynn-Wall-Ozawa and Coats Redfern models.

\section{Theoretical Considerations}

Non-isothermal methods have been used extensively for the determination of kinetic parameters. Many authors have employed different computational methods among which the Freeman Carroll, Flynn-Wall-Ozawa, Coats Redfern, Horowitz Metzger, Doyle modified by Zsako and SatavaSkvarfi methods are well known and have been tested by several researchers ${ }^{4}$.

The conversion rate $(\mathrm{dx} / \mathrm{dt})$ of a TGA's dynamic experiment in a constant heating rate $(\beta)$ is expressed as Equation $1^{[4,22]}$

$\frac{d x}{d t}=\frac{A}{\beta} \exp \left(\frac{-E_{a}}{R T}\right) f(x)$

where: $\mathrm{E}_{\mathrm{a}}$ is the activation energy of the process, $\mathrm{R}$ is the gas constant $\left(8.314 \mathrm{~J} \mathrm{~mol}^{-1} \mathrm{~K}^{-1}\right), \mathrm{f}(\mathrm{x})$ is the type of functional relation, $\mathrm{T}$ is the absolute temperature $(\mathrm{K})$, and $\mathrm{A}$ is the pre-exponential factor $\left(\mathrm{min}^{-1}\right)$.

Integration of Equation 1 within the limits of an initial temperature, $\mathrm{T}_{0}$, and the final temperature, $\mathrm{T}_{\mathrm{f}}$, corresponding the peak temperature, $T_{p}$, gives:

$g(x)=\frac{A}{\beta} \int_{T_{0}}^{T_{f}} e^{-E_{a} / R T} d T$

The Flynn-Wall-Ozawa (F-W-O) model is briefly described in the Equation 3. This isoconversional integral method suggested independently by Ozawa and Flynn and Wall uses Doyle's approximation of the temperature integral. From Equation 2 considers the term $\mathrm{g}(\mathrm{x})$ constant in a fix conversion rate and using Doyle's approximation, the result of the integration after taking logarithms is ${ }^{22-25}$.

$\log (\beta)=\log \left[\frac{A E_{a}}{g(x) R}\right]-2.315-0.457 \frac{E_{a}}{R T}$

where $\beta, A, E_{a}, R$ and $T$ have their usual significance.

Using the Equation 3 the activation energy may be determined from the slope of the line generated in the plot of $\log (\beta)$ versus $1000 / \mathrm{T}$ obtained at several heating rates.
Knowing the process activation energy, the necessary time for the material decomposes in a specific fraction can be determined by the Equation 4 for different temperatures ${ }^{26,27}$ :

$\log \left(t_{f}\right)=\frac{E_{a}}{2.303 \cdot R \cdot T_{f}}+\log \left(\frac{E_{a}}{R \cdot \beta}\right)-a$

where $t_{f}$ is the life time of the material for a temperature $T_{f}$ and for a given fraction of degraded material or conversion degree, $a$ is a tabled value dependant of $E_{a}$ and $T_{f}$, and $\beta$ is the heating rate nearest the mid-point of the experimental heating rates ${ }^{22-25}$.

The Coats Redfern model also can be used for determine decomposition kinetics. Otherwise than considered by Flynn-Wall-Ozawa model, it considers the functional conversion relation, which depends on relation mechanism type $(f(x))$. Using an asymptotic approximation to solve the Equation 2, the Equation 5 it may be obtained ${ }^{23}$ :

$\ln \left[\frac{g(x)}{T^{2}}\right]=\ln \left[\frac{A R}{\beta T}\right]-\frac{E}{R T}$

According to the different degradation processes, with the theoretic function $\mathrm{g}(\mathrm{x})$ obtained from the functions listed, the activation energy can be obtained by the plot of $\ln [\mathrm{g}(\alpha) /$ $\mathrm{T}^{2}$ ] versus $1000 / \mathrm{T}$. Table 1 shows the algebraic expressions for $\mathrm{g}(\mathrm{x})$ more frequently used in solid state processes $^{23}$.

\section{Experimental}

\subsection{Materials}

In this work the semi crystalline thermoplastic polymer LARPEEK 10 (PEEK), manufactured by the ICI Company and commercialized by the LATI Thermoplastics Company in powder form was studied.

\subsection{Non-isothermal TGA analyses}

The thermogravimetric analyses were carried in a SII Nanotechnology - Seiko equipment, Model EXSTAR6000, previously calibrated with metallic standards. The PEEK samples $(\sim 10 \mathrm{mg})$ were encapsulated in a standard platinum sample pan and the polymer was heated until $1000^{\circ} \mathrm{C}$ in four different heatings rates: $5^{\circ} \mathrm{C} \cdot \mathrm{min}^{-1}, 10^{\circ} \mathrm{C} \cdot \mathrm{min}^{-1}, 15^{\circ} \mathrm{C} \cdot \mathrm{min}^{-1}$ and $20^{\circ} \mathrm{C} \cdot \mathrm{min}^{-1}$. The procedure was carried both in synthetic air and nitrogen with $99.999 \%$ of purity atmospheres and flow of $100 \mathrm{~mL} \cdot \mathrm{min}^{-1}$. The plots of weight loss were obtained and the decomposition kinetics was studied based on FlynnWall-Ozawa (F-W-O) and Coats Redfern models.

\section{Results and Discussion}

\subsection{Nitrogen atmosphere}

The Figure 1 and 2 show the thermogravimetric plots and its first order derivatives (DTG), respectively, for the PEEK in nitrogen atmosphere in the four heating rates. The Table 2 shows the mainly PEEK thermal parameters obtained from Figure 1 and 2.

The thermogravimetric plots show two step decomposition processes of PEEK (Figure 1 and 2). In the 
Table 1. Algebraic expressions for $\mathrm{g}(\mathrm{x})$ for the most common solid state mechanisms ${ }^{23}$.

\begin{tabular}{|c|c|}
\hline Symbol & Solid state process \\
\hline \multicolumn{2}{|l|}{ Sigmoidal curves } \\
\hline A $2[-\ln (1-\alpha)]^{2}$ & Nucleation and growth (Avrami Equation 1) \\
\hline A3 $[-\ln (1-\alpha)]^{3}$ & Nucleation and growth (Avrami Equation 2) \\
\hline A $4[-\ln (1-\alpha)]^{4}$ & Nucleation and growth (Avrami Equation 3) \\
\hline \multicolumn{2}{|l|}{ Decelerate curves } \\
\hline $\mathrm{R} 1 \alpha$ & Phase boundary controlled reaction (one-dimensional movement) \\
\hline $\mathrm{R} 22\left[1-\ln (1-\alpha)^{1 / 2}\right.$ & Phase boundary controlled reaction (contracting area) \\
\hline $\mathrm{R} 33\left[1-\ln (1-\alpha)^{1 / 3}\right.$ & Phase boundary controlled reaction (contracting volume) \\
\hline D1 $\alpha^{2}$ & One-dimensional diffusion \\
\hline $\mathrm{D} 2(1-\alpha) \ln (1-\alpha)+\alpha$ & Two-dimensional diffusion (Valensi equation) \\
\hline D3 $\left[1-(-\alpha)^{1 / 3}\right]^{2}$ & Three-dimensional diffusion (Jander equation) \\
\hline $\mathrm{D} 4[1-(2 / 3) \alpha]-(1-\alpha)^{2 / 3}$ & Three-dimensional diffusion (Ginstlinge-Brounshtein equation) \\
\hline $\mathrm{F} 1-\ln (1-\alpha)$ & Random nucleation with one nucleus on the individual particle \\
\hline $\mathrm{F} 2 \frac{1}{1-\alpha}$ & Random nucleation with two nucleus on the individual particle \\
\hline F3 $\frac{1}{(1-\alpha)^{2}}$ & Random nucleation with three nucleus on the individual particle \\
\hline
\end{tabular}

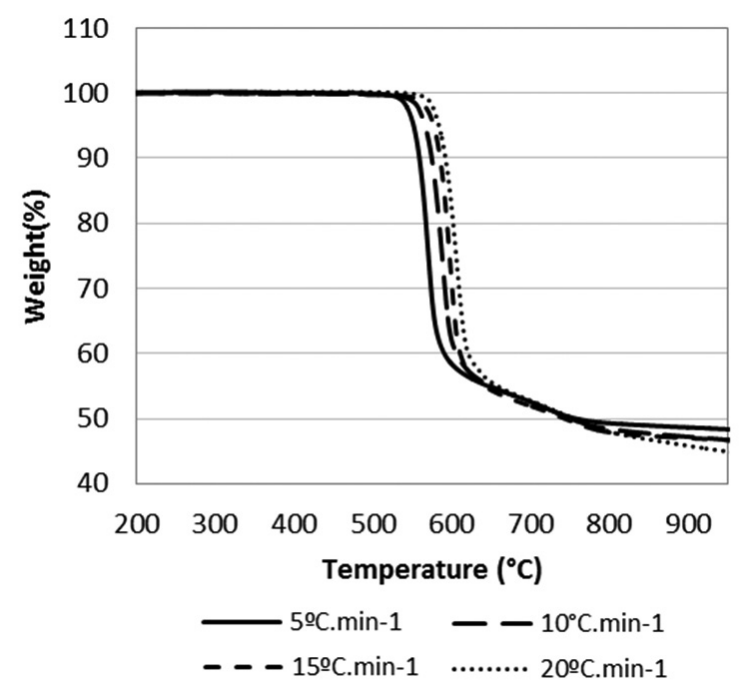

Figure 1. TGA curves of PEEK in nitrogen atmosphere for the heating rates of $5{ }^{\circ} \mathrm{C} \cdot \mathrm{min}^{-1} ; 10{ }^{\circ} \mathrm{C} \cdot \mathrm{min}^{-1} ; 15^{\circ} \mathrm{C} \cdot \mathrm{min}^{-1}$ and $20{ }^{\circ} \mathrm{C} \cdot \mathrm{min}^{-1}$.

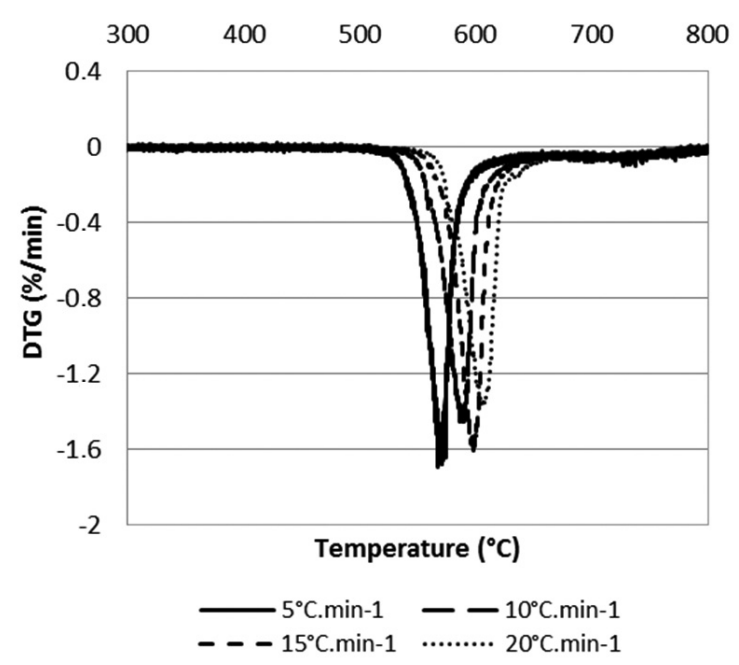

Figure 2. DTG curves of PEEK in nitrogen atmosphere for the heating rates of $5{ }^{\circ} \mathrm{C} \cdot \mathrm{min}^{-1} ; 10^{\circ} \mathrm{C} \cdot \mathrm{min}^{-1} ; 15^{\circ} \mathrm{C} \cdot \mathrm{min}^{-1}$ and $20{ }^{\circ} \mathrm{C} \cdot \mathrm{min}^{-1}$.

Table 2. Thermal characteristics of PEEK for the heating rates of $5{ }^{\circ} \mathrm{C} \cdot \mathrm{min}^{-1} ; 10^{\circ} \mathrm{C} \cdot \mathrm{min}^{-1} ; 15^{\circ} \mathrm{C} \cdot \mathrm{min}^{-1}$ and $20^{\circ} \mathrm{C} \cdot \mathrm{min}^{-1}$ in nitrogen atmosphere.

\begin{tabular}{ccccc}
\hline Heating rates & $\mathbf{5}^{\circ} \mathbf{C} \cdot \mathbf{m i n}^{\mathbf{- 1}}$ & $\mathbf{1 0}{ }^{\circ} \mathbf{C} \cdot \mathbf{m i n}^{\mathbf{- 1}}$ & $\mathbf{1 5}^{\circ} \mathbf{C} \cdot \mathbf{m} \mathbf{n}^{\mathbf{- 1}}$ & $\mathbf{2 0}^{\circ} \mathbf{C} \cdot \mathbf{m i n}^{\mathbf{- 1}}$ \\
\hline $\mathrm{t}_{\text {onset }}\left({ }^{\circ} \mathrm{C}\right)$ & 526 & 537 & 562 & 572 \\
$\mathrm{t}_{\text {max }}\left({ }^{\circ} \mathrm{C}\right)$ & 567 & 588 & 599 & 605 \\
Residue $(\%)$ & 47.9 & 46.3 & 46.4 & 44.2 \\
\hline
\end{tabular}

first decomposition step, random chain scission of the ether and ketone bonds is believed to be the main mechanism, with phenol being the predominant degradation product with smaller amounts of other compounds like benzene and dibenzofuran. However, cleavage of the carbonyl bond will lead to radical intermediates that are more stable due to resonance effects and would be expected to predominate. In the second decomposition stage, occurs a slower volatilization of the residue, with about 46 to $50 \%$ of residue remaining in $900{ }^{\circ} \mathrm{C}^{[5,28]}$. 
It is possible to observe from the onset temperatures that the PEEK starts its thermal decomposition in about $526{ }^{\circ} \mathrm{C}$. The onset temperatures tend to be dislocated to higher temperatures in the plots when using higher heating rates, although this effect was already expected because the polymer must absorb energy before thermally decomposes, and if the heating rate is higher, the equipment detects the decomposition in higher temperatures. Rapid and significant mass loss occurs just below $600{ }^{\circ} \mathrm{C}$ resulting in the volatilisation of around $45 \%$ of the polymer mass, the remaining polymer mass appears to be carbonaceous char. Finally, it can be observed that the PEEK left a great amount of residue $(\sim 45 \%)$. This has also been observed by other authors and has been attributed to the loss of, mainly, phenols as decomposition products, although carbon monoxide (CO) and carbon dioxide $\left(\mathrm{CO}_{2}\right)$ have also been identified as evolving rapidly over this temperature range possibly as a by-product of the decomposition of PEEK to phenols. This is followed by a slower process of volatilisation of the residue, with over $45 \%$ still present even at $1000{ }^{\circ} \mathrm{C}^{[5]}$.

Using the Equation 3, the $\log (\beta)$ vesus $1000 / \mathrm{T}$ was plotted for the conversion rates of $2.5 \%, 5.0 \%, 7.5 \%, 10 \%$, $12.5 \%$ and $15 \%$, and it is showed in Figure 3. This rates were chosen because in the Flynn-Wall-Ozawa method only conversion values in the range 5 and $20 \%$ can be used ${ }^{22}$. The good mathematic adjust of the experimental points to the line's equation $\left(R^{2 \geq 0}, 997\right)$ indicates that the Flynn-WallOzawa model adjusts to the kinetic decomposition study of PEEK in nitrogen atmosphere.

The lines' slope obtained in Figure 3 can be correlated to the Equation 3. Thus the activation energies can be calculated directly using each of the slopes values obtained for the different heating rates and equaling its values to the item $0.457 \mathrm{E}_{\mathrm{a}} / \mathrm{R}$ of Equation 3 . The activation energy for the different conversion rates are presented in Figure 4. It can be observed that the activation energies are in the range of about 234 to $238 \mathrm{~kJ} / \mathrm{mol}$.

Using the activation energy obtained for the conversion rate of $5 \%$, the lifetime of the material in relation to different temperatures was made using Equation 4. The conversion rate of $5 \%$ was chosen because it corresponds to the beginning of the degradation process and this level of degradation can cause a significant decrease of the mechanical properties of material.

The analysis of Figure 5 shows that the material has high thermal stability. The necessary time for the material decomposes in $5 \%$ is approximately 216 years if it is submitted to temperatures of $350{ }^{\circ} \mathrm{C}$.

Many authors have used both isoconventional and discrimination methods in decomposition kinetics studies $^{29-32}$. The comparison of the activation energies obtained by the Flynn-Wall-Ozawa and the CoatsRedfern models can be useful to estimate the probable thermodegradation kinetic mechanism of the material. In that context, using the algebraic expressions listed in Table 1 , the process adequacy of material's thermal decomposition to each of the solid state processes was verified. In this way, the activation energies and the correlation coefficients for the rates of $5^{\circ} \mathrm{C} \cdot \mathrm{min}^{-1} ; 10^{\circ} \mathrm{C} \cdot \mathrm{min}^{-1} ; 15^{\circ} \mathrm{C} \cdot \mathrm{min}^{-1}$ and $20^{\circ} \mathrm{C} \cdot \mathrm{min}^{-1}$ are presented in the Table 3.

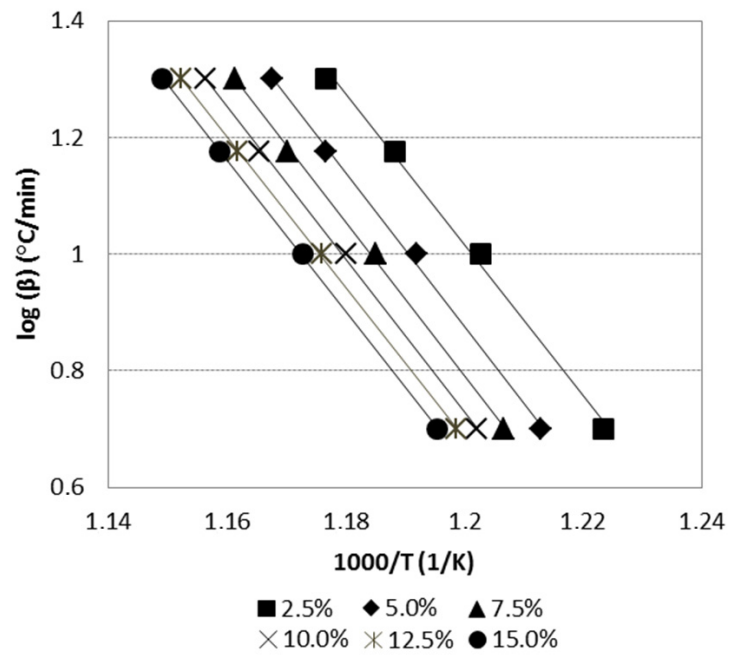

Figure 3. Plot of $\log (\mathrm{b})$ versus 1000/T and mathematical adjustment by least squares method for the conversion rates of $2.5 \%, 5 \%, 7.5 \%$, $10 \%, 12.5 \%$ and $15 \%$.

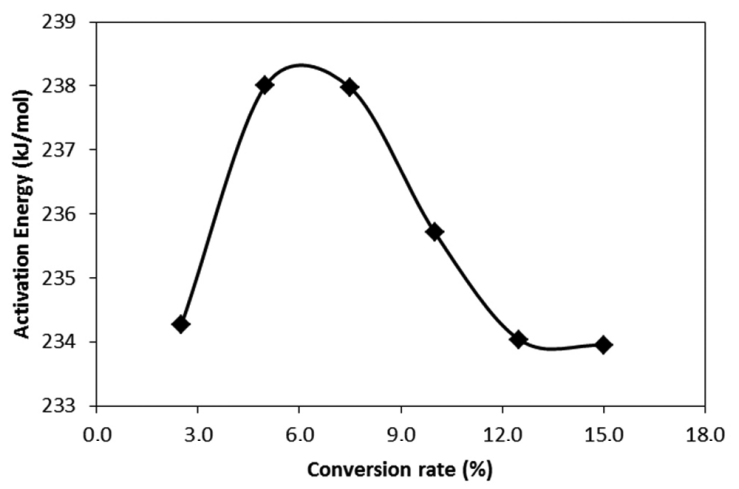

Figure 4. Activation Energies obtained for the conversion rates of $2.5 \%, 5.0 \%, 7.5 \%, 10.0 \%, 12.5 \%$ and $15.0 \%$

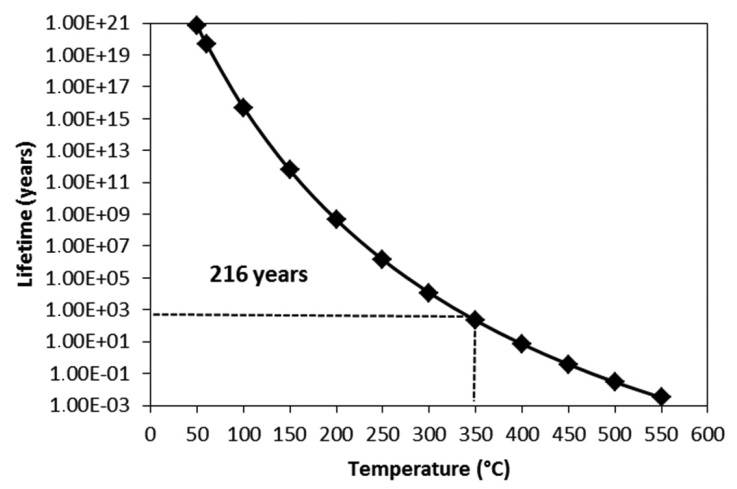

Figure 5. Lifetime versus necessary temperature for the PEEK decomposes in $5 \%$.

In order to determine which of the mechanisms listed in the Table 3 had better adjustment to the kinetic process of thermal decomposition, the experimental points' adequacy to a line equation was tested by comparing the listed correlation coefficients. Besides that, the activation 
Table 3. Activation energies for the heating rates of $5{ }^{\circ} \mathrm{C} \cdot \mathrm{min}^{-1} ; 10^{\circ} \mathrm{C} \cdot \mathrm{min}^{-1} ; 15^{\circ} \mathrm{C} \cdot \mathrm{min}^{-1}$ and $20^{\circ} \mathrm{C} \cdot \mathrm{min}^{-1}$ in nitrogen atmosphere.

\begin{tabular}{ccccccccc}
\hline Mechanism & \multicolumn{2}{c}{$\mathbf{5}^{\circ} \mathbf{C} \cdot \mathbf{m i n}^{-1}$} & \multicolumn{2}{c}{$\mathbf{1 0}^{\circ} \mathbf{C} \cdot \mathbf{m i n}^{-\mathbf{1}}$} & \multicolumn{2}{c}{$\mathbf{1 5}^{\circ} \mathbf{C} \cdot \mathbf{m i n}^{-1}$} & \multicolumn{2}{c}{$\mathbf{2 0}^{\circ} \mathbf{C . \mathbf { m i n } ^ { - 1 }}$} \\
\cline { 2 - 9 } & $\mathbf{E}(\mathbf{k J} / \mathbf{m o l})$ & $\mathbf{R}$ & $\mathbf{E}(\mathbf{k J} / \mathbf{m o l})$ & $\mathbf{R}$ & $\mathbf{E}(\mathbf{k J} / \mathbf{m o l})$ & $\mathbf{R}$ & $\mathbf{E}(\mathbf{k J} / \mathbf{m i n})$ & $\mathbf{R}$ \\
\hline A2 & 1096.62 & 0.9999 & 1012.81 & 0.9994 & 724.52 & 0.9804 & 1098.45 & 0.9960 \\
A3 & 1651.83 & 0.9999 & 1526.28 & 0.9994 & 1093.87 & 0.9807 & 1654.90 & 0.9960 \\
A4 & 2207.53 & 0.9999 & 2040.17 & 0.9994 & 1463.68 & 0.9808 & 2211.77 & 0.9960 \\
R1 & 521.66 & 0.9996 & 481.08 & 0.9989 & 342.10 & 0.9800 & 522.00 & 0.9945 \\
R2 & -5.89 & 0.7795 & 4.25 & 0.6863 & -1.17 & 0.0953 & 5.87 & 0.8390 \\
R3 & -0.75 & 0.0507 & -1.95 & 0.3134 & -5.66 & 0.8130 & -1.10 & 0.1511 \\
D1 & 1057.04 & 0.9996 & 976.15 & 0.9989 & 698.44 & 0.9808 & 1058.29 & 0.9947 \\
D2 & 1070.09 & 0.9997 & 988.20 & 0.9991 & 707.01 & 0.9807 & 1071.51 & 0.9951 \\
D3 & 87.64 & 0.9973 & 79.83 & 0.9985 & 53.17 & 0.9647 & 87.60 & 0.9998 \\
D4 & 1074.50 & 0.9998 & 992.28 & 0.9991 & 709.92 & 0.9806 & 1076.00 & 0.9953 \\
F1 & 541.43 & 0.9999 & 499.42 & 0.9994 & 355.15 & 0.9796 & 542.09 & 0.9959 \\
F2 & 26.39 & 0.8646 & 23.23 & 0.8629 & 12.24 & 0.6662 & 26.48 & 0.9080 \\
F3 & 66.52 & 0.9099 & 60.45 & 0.9138 & 38.70 & 0.8323 & 67.26 & 0.9405 \\
\hline
\end{tabular}

energy values were compared with the values founded in Flynn-Wall-Ozawa method. So the activation energy of D3 mechanism (Three-dimensional diffusion - Jander equation) had better adjustment to the decomposition process of the material once its value was the closest one to the obtained in the F-W-O model. The mathematical adjustment to the cited mechanism is showed in the Figure 6.

\subsection{Synthetic air atmosphere}

The Figure 7 and 8 show the thermogravimetric plots and their first order derivatives, respectively, to the PEEK in synthetic air atmosphere at the four heating rates. The Table 4 shows the mainly thermal characteristics of PEEK obtained from the Figure 7 and 8.

The thermogravimetric plot's analysis shows that the thermal decomposition of PEEK occurs in a more complex way then observed in nitrogen atmosphere. It can be observed at least two partially overlapped peaks in the first order derivatives in all heating rates. This behavior observed is mainly due the oxygen presence, which promotes a serie of oxidative reactions in the material. In this instance, the second decomposition step is attributed to the oxidation of the carbonaceous char formed as a result of the first decomposition step. It is possible to notice from the onset temperatures that the PEEK starts its thermal decomposition in about $507^{\circ} \mathrm{C}$.

This temperature is inferior to that observed in nitrogen atmosphere, which shows that the thermal stability of the material decreases in oxygen presence. The final residue is also much inferior to the previous tests, due to the volatile composes released in the oxidation reactions.

Using the Equation 3, the $\log (\beta)$ vesus $1000 / \mathrm{T}$ plot was made for the conversion taxes of $2.5 \%, 5.0 \%, 7.5 \%, 10.0 \%$, $12.5 \%$, and $15.0 \%$, and it is showed in Figure 9. In this case, it can be observed a good mathematical adjustment of the experimental points to the line equations, although this adjustment wasn $t$ as good as observed in nitrogen

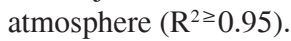

The slopes of lines obtained in Figure 9 can be correlated to the $0.457 \mathrm{E}_{\mathrm{a}} / \mathrm{R}$ item of Equation 3. So the values of

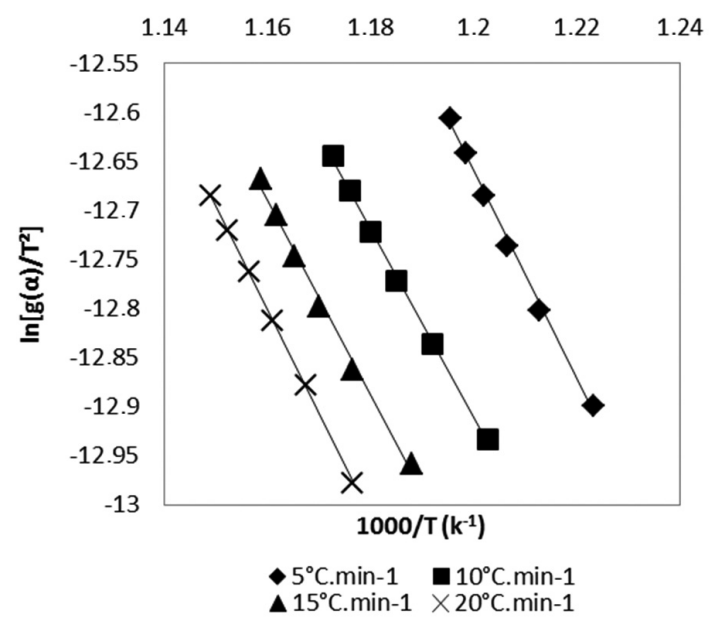

Figure 6. D3 equation adjusted to the Coats-Redfern method in the heating rates of $5{ }^{\circ} \mathrm{C} \cdot \mathrm{min}^{-1} ; 10^{\circ} \mathrm{C} \cdot \mathrm{min}^{-1} ; 15^{\circ} \mathrm{C} \cdot \mathrm{min}^{-1}$ and $20{ }^{\circ} \mathrm{C} \cdot \mathrm{min}^{-1}$.

activation energy to the different conversion rates are presented in Figure 10. It can be observed that the activation energies are in the range of about 115 to $165 \mathrm{~kJ} / \mathrm{mol}$. The obtained data shows that the activation energy is significantly reduced in the presence of oxygen. This is already expected once the decomposition process of PEEK in nitrogen starts with random chain scission of the ether and ketone bonds, while the oxygen presence permits oxidation reactions to occur in addition to the chain scission reactions5. The oxidation reactions requires less activation energy to occur and promotes different decomposition mechanisms than the observed in nitrogen atmosphere.

The deviation in activation energies relative to the conversion rates can be explained by the different reactions that take place in the process of PEEK decomposition. Initially random chain scission of the ether and ketone bonds are the main reaction, which require less activation energies than the following ones, with intermediate radicals that are 
Table 4. Thermal characteristics of PEEK for the heating rates of $5^{\circ} \mathrm{C} \cdot \mathrm{min}^{-1} ; 10^{\circ} \mathrm{C} \cdot \mathrm{min}^{-1} ; 15^{\circ} \mathrm{C} \cdot \mathrm{min}^{-1}$ and $20^{\circ} \mathrm{C} \cdot \mathrm{min}^{-1}$ in air atmosphere.

\begin{tabular}{ccccc}
\hline Heating rates & $\mathbf{5}^{\circ} \mathbf{C} \cdot \mathbf{m i n}^{-\mathbf{1}}$ & $\mathbf{1 0}{ }^{\circ} \mathbf{C} \cdot \mathbf{m i n}^{-\mathbf{1}}$ & $\mathbf{1 5}^{\circ} \mathbf{C} \cdot \mathbf{m i n}^{-\mathbf{1}}$ & $\mathbf{2 0}^{\circ} \mathbf{C} \cdot \mathbf{m i n}^{-\mathbf{1}}$ \\
\hline $\mathrm{t}_{\text {onset }}\left({ }^{\circ} \mathrm{C}\right)$ & 507 & 531 & 542 & 546 \\
${ }^{{ }_{\text {máx }}\left({ }^{\circ} \mathrm{C}\right)}$ & 600 & 587 & 602 & 630 \\
Residue $(\%)$ & 0.41 & 0.08 & 0.00 & 0.02 \\
\hline
\end{tabular}

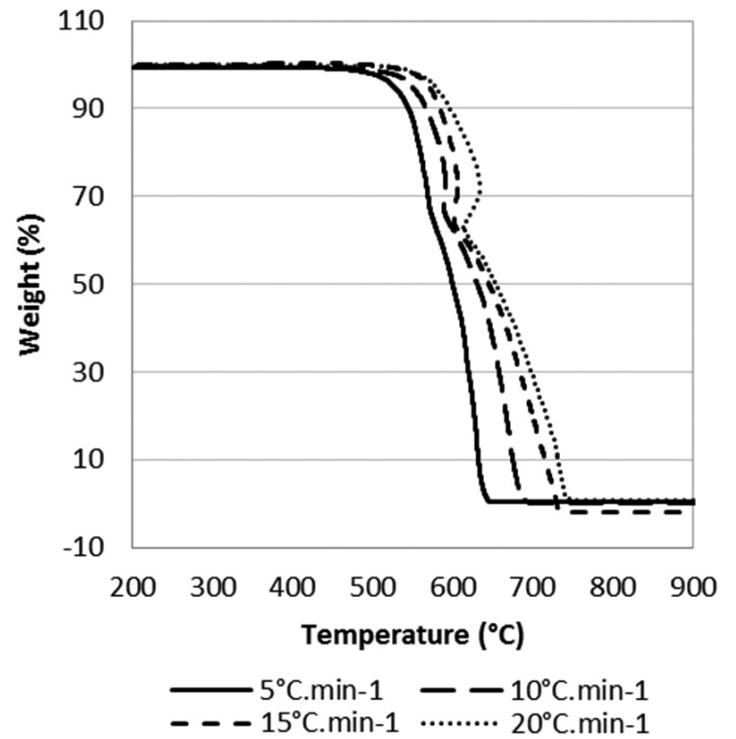

Figure 7. TGA curves of PEEK in Synthetic air atmosphere for the heating rates of $5{ }^{\circ} \mathrm{C} \cdot \mathrm{min}^{-1} ; 10^{\circ} \mathrm{C} \cdot \mathrm{min}^{-1} ; 15^{\circ} \mathrm{C} \cdot \mathrm{min}^{-1}$ and $20{ }^{\circ} \mathrm{C} \cdot \mathrm{min}^{-1}$.

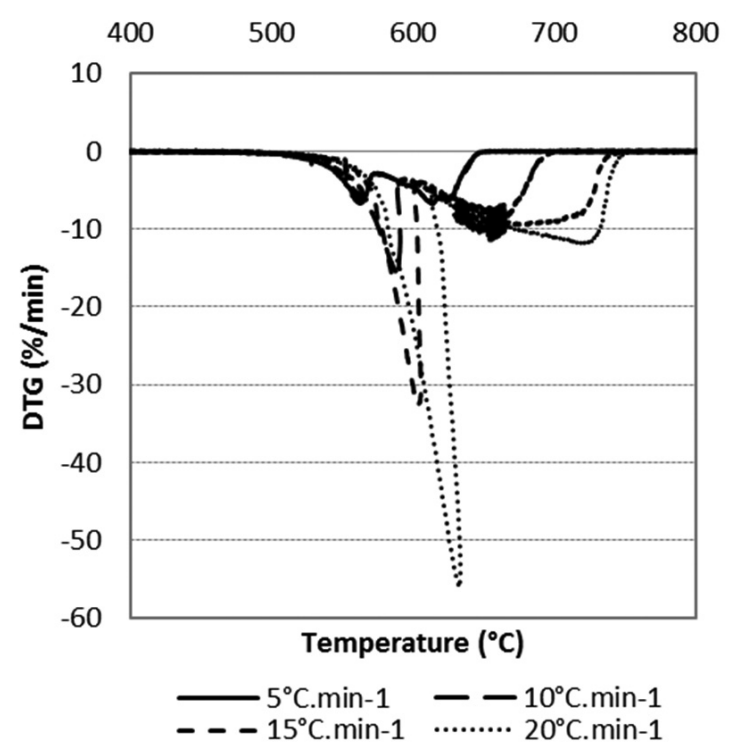

Figure 8. DTG curves for the heating rates of $5{ }^{\circ} \mathrm{C} \cdot \mathrm{min}^{-1}$; $10{ }^{\circ} \mathrm{C} \cdot \mathrm{min}^{-1} ; 15^{\circ} \mathrm{C} \cdot \mathrm{min}^{-1}$ and $20{ }^{\circ} \mathrm{C} \cdot \mathrm{min}^{-1}$.

more stable. Subsequently the decomposition occurs with a slower volatilization of the residue, which again requires less activation energy to take place.

Using the activation energy obtained to the conversion rate of $5 \%$, the lifetime calculus in relation to different

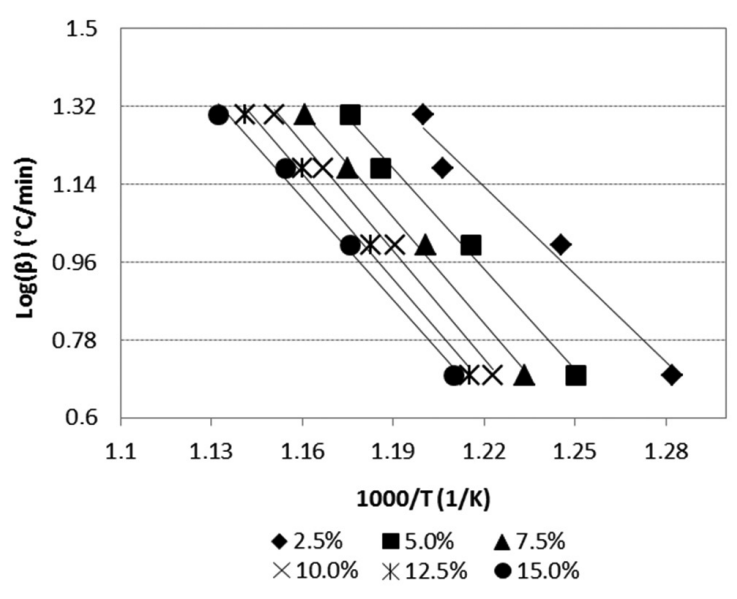

Figure 9. Plot of log b versus 1000/T and mathematical adjustment by least squares method for the conversion rates of $2.5 \%, 5 \%, 7.5 \%$, $10 \%, 12.5 \%$ and $15 \%$.

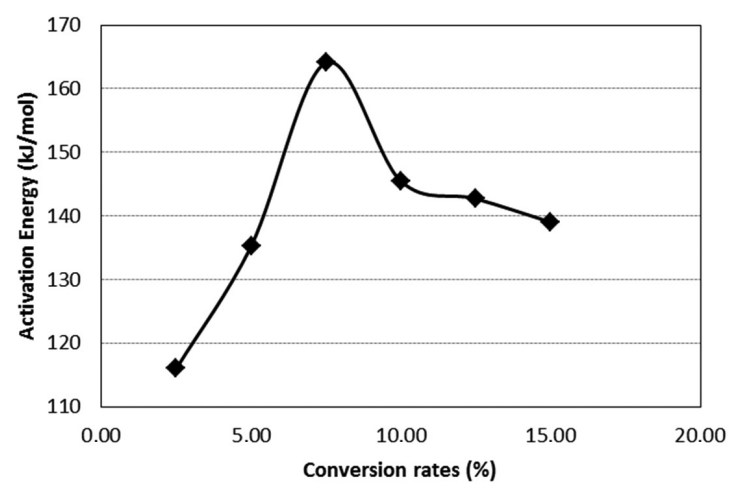

Figure 10. Activation Energies obtained for the conversion rates of $2.5 \%, 5.0 \%, 7.5 \%, 10.0 \%, 12.5 \%$ and $15.0 \%$.

temperatures was made using Equation 4, as shown in Figure 11.

The Figure 11 analysis shows that the thermal stability of material is highly compromised by the exposure of a non-inert atmosphere. The necessary time for the material decomposes in $5 \%$ is about 1,05 year if it is exposed to the temperature of $350{ }^{\circ} \mathrm{C}$.

Using the algebraic expressions listed in Table 3, the adequacy of thermal decomposition of material in each of solid-state process was verified. In this way, the activation energies (E) and the correlation coefficients $\left(\mathrm{R}^{2}\right)$ for the heating rates of $5^{\circ} \mathrm{C} \cdot \mathrm{min}^{-1} ; 10^{\circ} \mathrm{C} \cdot \mathrm{min}^{-1} ; 15^{\circ} \mathrm{C} \cdot \mathrm{min}^{-1}$ and $20^{\circ} \mathrm{C} \cdot \mathrm{min}^{-1}$ are listed in Table 5 .

In order to determine which of the mechanisms listed in Table 5 had better adjustment to the thermal decomposition process, the verification of the adequacy of the experimental 
Table 5. Activation energies for the heating rates of $5^{\circ} \mathrm{C} \cdot \mathrm{min}^{-1} ; 10^{\circ} \mathrm{C} \cdot \mathrm{min}^{-1} ; 15^{\circ} \mathrm{C} \cdot \mathrm{min}^{-1}$ and $20^{\circ} \mathrm{C} \cdot \mathrm{min}^{-1}$ in air atmosphere.

\begin{tabular}{ccccccccc}
\hline Mechanism & \multicolumn{2}{c}{$\mathbf{5}^{\circ} \mathbf{C} \cdot \mathbf{m i n}^{-1}$} & \multicolumn{2}{c}{$\mathbf{1 0}^{\circ} \mathbf{C} \cdot \mathbf{m i n}^{-\mathbf{1}}$} & \multicolumn{2}{c}{$\mathbf{1 5}^{\circ} \mathbf{C} \cdot \mathbf{m i n}^{-1}$} & \multicolumn{2}{c}{$\mathbf{2 0}^{\circ} \mathbf{C} \cdot \mathbf{m i n}^{-\mathbf{1}}$} \\
\cline { 2 - 10 } & $\mathbf{E}(\mathbf{k J} / \mathbf{m o l})$ & $\mathbf{R}$ & $\mathbf{E}(\mathbf{k J} / \mathbf{m o l})$ & $\mathbf{R}$ & $\mathbf{E}(\mathbf{k J} / \mathbf{m o l})$ & $\mathbf{R}$ & $\mathbf{E}(\mathbf{k J} / \mathbf{m i n})$ & $\mathbf{R}$ \\
\hline A2 & 409.68 & 0.9929 & 433.30 & 0.9972 & 588.19 & 0.9996 & 424.43 & 0.9340 \\
A3 & 621.20 & 0.9930 & 656.82 & 0.9973 & 889.35 & 0.9996 & 643.78 & 0.9353 \\
A4 & 832.90 & 0.9931 & 880.54 & 0.9973 & 1190.81 & 0.9996 & 863.33 & 0.9360 \\
R1 & 190.81 & 0.9941 & 201.94 & 0.9980 & 276.37 & 0.9995 & 196.97 & 0.9258 \\
R2 & -6.14 & 0.7086 & -5.83 & 0.6964 & -3.24 & 0.4866 & -4.43 & 0.5107 \\
R3 & -8.51 & 0.9658 & -8.58 & 0.9699 & -7.06 & 0.9388 & -8.94 & 0.9834 \\
D1 & 394.98 & 0.9945 & 417.62 & 0.9981 & 566.82 & 0.9995 & 408.19 & 0.9307 \\
D2 & 399.81 & 0.9939 & 422.77 & 0.9978 & 573.84 & 0.9996 & 413.52 & 0.9318 \\
D3 & 25.09 & 0.9599 & 26.96 & 0.9771 & 40.86 & 0.9930 & 26.09 & 0.8881 \\
D4 & 401.45 & 0.9938 & 424.52 & 0.9977 & 576.23 & 0.9960 & 415.33 & 0.9322 \\
F1 & 198.16 & 0.9924 & 209.79 & 0.9970 & 287.06 & 0.9995 & 205.08 & 0.9295 \\
F2 & 1.57 & 0.0812 & 2.18 & 0.1592 & 7.61 & 0.6241 & -2.22 & 0.2577 \\
F3 & 16.48 & 0.7050 & 18.10 & 0.7610 & 29.30 & 0.8584 & 18.70 & 0.8588 \\
\hline
\end{tabular}

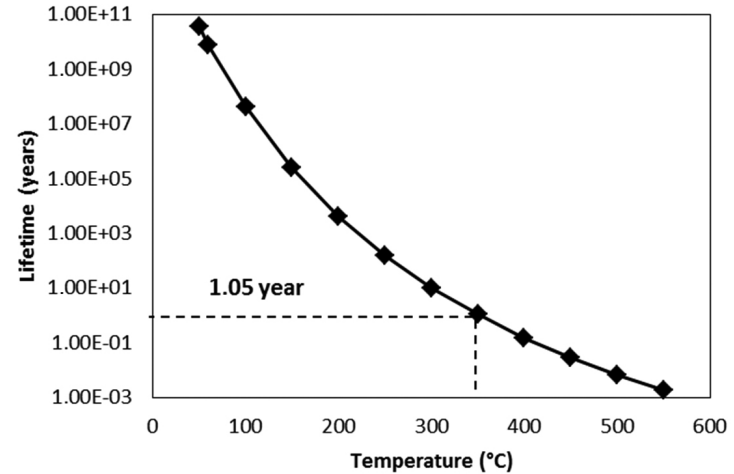

Figure 11. Lifetime versus necessary temperature for the PEEK decomposes in $5 \%$.

points to a line equation was verified by comparing the correlating coefficients listed. Besides that, the activation energy values were compared with the values founded by Flynn-Wall-Ozawa method. So the R1 mechanism (Phase boundary controlled reaction (one-dimensional movement)) has better adjustment to the decomposition kinetics of the material. The difference observed in the mechanisms of samples heated in nitrogen atmosphere is due the availability of oxidation reactions in the system, which requires less activation energies to occur and promotes a more complex decomposition mechanism. In that context, one should predict the decomposition process of the PEEK in relation to the real working environment rather than expecting a unique most likely mechanism to occur.

It can be also observed a tendency in getting lower activation energies in the different models of Table 3 when using heating rates of $15^{\circ} \mathrm{C} / \mathrm{min}$ and also in getting higher activation energies in the different models of Table 5 when using heating rates of $15^{\circ} \mathrm{C} / \mathrm{min}$. A tendency of the same polymeric system to getting higher and lower activation energies in specifics heating rates for different models was also observed in the work of WU Songquan et al. ${ }^{33}$ and most likely occurs due the decomposition mechanisms

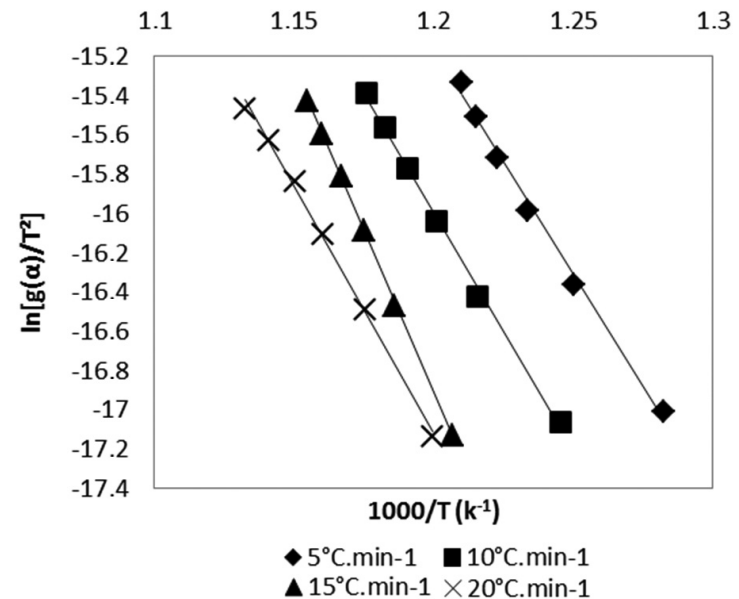

Figure 12. R1 equation adjusted to the Coats-Redfern method in the heating rates of $5{ }^{\circ} \mathrm{C} \cdot \mathrm{min}^{-1} ; 10^{\circ} \mathrm{C} \cdot \mathrm{min}^{-1} ; 15^{\circ} \mathrm{C} \cdot \mathrm{min}^{-1}$ and $20{ }^{\circ} \mathrm{C} \cdot \mathrm{min}^{-1}$.

dependence both to temperature and heating rates. In nitrogen atmosphere, the heating hate of $15^{\circ} \mathrm{C} / \mathrm{min}$ promotes the polymer decomposition reactions to occur in higher temperatures, which tends to require lower activation energies. The opposite behavior observed in air atmosphere may occur due the higher heating hates of to permit lower diffusion of oxygen in the sample, demanding more energy to the thermo-oxidation process to occur ${ }^{6}$. The mathematical adjustment for the cited mechanism is shown in Figure 12. It was observed some difference in the values of activations energies obtained by F-W-O models and the ones from the better adjustments of Coats-Redfern model, both in nitrogen and air atmospheres. It is important to emphasize that he F-W-O is an integral method which is independent of the degradation mechanism and alternatively the Coats Redfern model is one of the most widely used procedures for the determination of the reaction mechanism ${ }^{29,31}$. In that context, the better adjustment of the Coats-Redfern model 
is based both on the experimental data fitting $\left(\mathrm{R}^{2} \rightarrow 1\right)$ and the values of activation energies previously obtained in the F-W-O model. Therefore the activation energies of F-W-O are way more accurate to the decomposition Kinects of the material and the Coats Redfern model has the main goal of establishing its most probable decomposition mechanism.

\section{Conclusions}

The thermogravimetric analyses of PEEK in nitrogen atmosphere showed that its thermal decomposition occurred in two steps. It was observed by the onset temperatures that the PEEK starts its decomposition in about $526{ }^{\circ} \mathrm{C}$ and generated a great amount of residue (about $45 \%$ ). The decomposition kinetic study showed that the material has high thermal stability. The necessary time for the material decomposes in $5 \%$ is of approximately 216 years if it is submitted to temperatures of $350{ }^{\circ} \mathrm{C}$. The kinetics study by Coats Redfern showed that the D3 mechanism (Three-dimensional diffusion (Jander equation)) had better adjustment to the decomposition kinetics of the material.

\section{References}

1. Avakian P, Gardner KH and Matheson RR. A comment on crystallization in PEKK and PEEK resins. Journal of Polymer Science. 1990; 28:243-246.

2. Flynn JH and Wall LA. General Treatment of the Thermogravimetry of Polymers. National Bureau of Standards Polymers. 1966; 70:20234.

3. Snyder PA, Maswadeh WM, Dworzanski, Charles HWJP and Tripathi A. Comparison of the kinetics of thermal decomposition of biological substances between thermogravimetry and a fielded pyrolysis bioaerosol detector. Polym Degrad Stab. Thermochimica Acta. 2005; 437:87-99. http://dx.doi. org/10.1016/j.tca.2005.06.022

4. Wahab MMM. Thermal decomposition kinetics of some new unsaturated polyesters. Thermochimica Acta. 1995; 256:271280. http://dx.doi.org/10.1016/0040-6031(94)02183-O

5. Patel P, Richard T, Richard H, McCabe W, Flath D, Grasmeder $D$ et al. Mechanism of Thermal Decomposition of Poly(Ether Ether Ketone) (PEEK) From a Review of Decomposition Studies. Polymer Degradation and Stability. 2010; 95:709718. http://dx.doi.org/10.1016/j.polymdegradstab.2010.01.024

6. Ramani R and Alam S. Composition optimization of PEEK/ PEI blend using model-free kinetics analysis. Thermochimica Acta. 2010; 511:179-188. http://dx.doi.org/10.1016/j. tca.2010.08.012

7. Perng LH. Thermal cracking characteristics of PEEK under different environments by the TG/FTIR technique. Journal of Polymer Science Part A: Polymer Chemistry. 1999; 37:45824590. http://dx.doi.org/10.1002/(SICI)10990518(19991215)37:24<4582::AID-POLA15>3.0.CO;2-Q

8. Nandan B, Kandpal LD and Mathur GN. Poly(Ether Ether Ketone)/Poly(Aryl Ether Sulphone) Blends: Thermal Degradation Behaviour. European Polymer Journal. 2003; 39:193-198. http://dx.doi.org/10.1016/S00143057(02)00170-2

9. Hay JN and Kemmish DJ. Thermal Decomposition of Poly(Aryl Ether Ketones). Polymer. 1987; 28:2047-2051. http://dx.doi.org/10.1016/0032-3861(87)90039-5
The thermogravimetric analyses of PEEK in synthetic air atmosphere showed that the thermal decomposition occurs in a more complex way then observed in nitrogen atmosphere. It can be observed at least two partially overlapped peaks in the first order derivatives in all used heating rates. The PEEK starts its thermal decomposition in about $507{ }^{\circ} \mathrm{C}$. This temperature is inferior to that observed in nitrogen atmosphere and the final residue is also much inferior to the previous tests.

The decomposition kinetic study showed that the thermal stability of material is highly compromised by the exposure of a non-inert atmosphere. The necessary time for the material decomposes in $5 \%$ is about 1,05 year if it is exposed to the temperature of $350{ }^{\circ} \mathrm{C}$. The $\mathrm{R} 1$ mechanism (Phase boundary controlled reaction (one-dimensional movement)) has better adjustment to the decomposition kinetics of the material.

\section{Acknowledgements}

The authors acknowledge financial support received from FAPESP and CNPq.

10. Vasconcelos GC, Mazur RL, Botelho EC, Rezende MC and Costa ML. Evaluation of Crystallization Kinetics of Polymer of Poly (Ether-Ketone-Ketone) and Poly (EtherEther-Ketone) by DSC. Journal of Aerospace Technology and Management. 2010; 2:155-162. http://dx.doi.org/10.5028/ jatm.2010.02026310

11. Flynn JH and Wall LA. A quick, direct method for the determination of activation energy from thermogravimetric data. Polymer Letters. 1966; 4:323-8. http://dx.doi.org/10.1002/ pol.1966.110040504

12. Levchik SV, Ivashkevich OA, Balabanovich AI, Lesnikovich AI, Gaponik PN and Costa L. Thermal decomposition of aminotetrazoles. Thermochimica Acta. 1992; 207:115-130. http://dx.doi.org/10.1016/0040-6031(92)80129-K

13. Achilias DS, Panayotidou E and Zuburtikudis I. Thermal degradation kinetics and isoconversional analysis of biodegradable poly(3-hydroxybutyrate)/organomodified montmorillonite nanocomposites. Thermochimica Acta. 2011; 514(1-2): 58-66. http://dx.doi.org/10.1016/j.tca.2010.12.003

14. Wang W, Schultz JM and Hsiao BS. Dynamic study of crystallization- and melting-induced phase separation in PEEK/ PEKK blends. Macromolecules. 1997; 30:4544-4550. http:// dx.doi.org/10.1021/ma9700921

15. Day M, Cooney JD and MacKinnon M. Degradation of contaminated plastics: a kinetic study. Polymer Degradation and Stability. 1995; 48:341-349. http://dx.doi.org/10.1016/01413910(95)00088-4

16. Wey MY and Chang CL. Kinetic study of polymer incineration. Polymer Degradation and Stability. 1995; 48:25-33. http:// dx.doi.org/10.1016/0141-3910(94)00125-R

17. Bockhorn H, Hornung A and Hornung U. Mechanisms and kinetics of thermal decomposition of plastics from isothermal and dynamic measurements. Journal of Analytical and Applied Pyrolysis. 1999; 50:77-101. http://dx.doi.org/10.1016/S01652370(99)00026-1

18. Jae DN and James CS. Generalized composite degradation kinetics for polymeric systems under isothermal and nonisothermal conditions. Journal of Polymer 
Science. 1992; 30:455-463. http://dx.doi.org/10.1002/ polb.1992.090300505

19. Naffakh M, Gomez MA, Marco C and Ellis G. Kinetic analysis of thermo-oxidative degradation of PEEK/thermotropic liquid crystalline polymer blends. Polymer Engineering \& Science. 2006; 46(2):129-138. http://dx.doi.org/10.1002/ pen.20439

20. Abate L, Calanna S, Pollicino A and Recca A. Thermal stability of a novel poly(ether ether ketone ketone)(PK99). Polymer Engineering and Science. 1996; 36:1782-1788 . http://dx.doi. org/10.1002/pen.10573

21. Kenny JM, Torre L and Nicolais L. Short- and long-term degradation of polymer-based composites. Thermochimica Acta. 1993; 227:97-106. http://dx.doi.org/10.1016/00406031(93)80253-7

22. Sengupta R, Sabharwal S, Bhowmick AK and Chaki TK. Thermogravimetric studies on Polyamide-6,6 modified by electron beam irradiation and by nanofillers. Polymer Degradation and Stability. 2006; 91:1311-1318. http://dx.doi. org/10.1016/j.polymdegradstab.2005.08.012

23. Barral L. Thermodegradation kinetics of a hybrid. European Polymer Journal. 2005; 41:1662-1666. http://dx.doi. org/10.1016/j.eurpolymj.2005.01.021

24. Zhou XY. Kinetics analysis of thermal degradation reaction of pva and pva/starch blends. Journal of Reinforced Plastics and Composites. 2009; 28:22. http://dx.doi. org/10.1177/0731684408093872

25. Ozawa T. A new method of analyzing thermogravimetric data. Bulletin of the Chemical Society of Japan. 1967; 38:1881-6. http://dx.doi.org/10.1246/bcsj.38.1881

26. American Society for Testing and Materials - ASTM. ASTM-E1641: Standard test method for decomposition kinetics by thermogravimetry. West Conshohocken: ASTM; 1999.
27. American Society for Testing and Materials - ASTM. ASTM-E1877: Standard practice for calculating thermal endurance of materials from thermogravimetric decomposition data. West Conshohocken: ASTM; 1999.

28. Moulinik P, Paroli RM, Wang ZY, Delgado AH, Guen AL, Qi Y et al. Investigating the degradation of thermoplastics by thermogravimetry-fourier transform infrared spectroscopy (TG-FTIR). Polymer Testing. 1996; 15(1):75-89. http://dx.doi. org/10.1016/0142-9418(95)00025-9

29. Manikandan G, Rajarajan G, Jayabharathi J and Thanikachalam V. Structural effects and thermal decomposition kinetics of chalcones under non-isothermal conditions. Arabian Journal of Chemistry. 2011; 4. In Press. http://dx.doi.org/10.1016/j. arabjc.2011.06.029

30. Yao F, Wu Q, Lei Y, Guo W and Xu Y. Thermal decomposition kinetics of natural fibers: Activation energy with dynamic thermogravimetric analysi. Polymer Degradation and Stability. 2008; 93:90-98. http://dx.doi.org/10.1016/j. polymdegradstab.2007.10.012

31. Omrani A and Hasankola SMM. Kinetic study on solid state thermal degradation of epoxy nanocomposite containing Octasilane polyhedral oligomeric silsesquioxane. Journal of Non-Crystalline Solids. 2012; 358:1656-1666. http://dx.doi. org/10.1016/j.jnoncrysol.2012.04.036

32. Meng X, Huang Y, Yu H and Lv Z. Thermal degradation kinetics of polyimide containing 2,6-benzobisoxazole units. Polymer Degradation and Stability. 2007; 92:962-967. http://dx.doi. org/10.1016/j.polymdegradstab.2007.03.005

33. Songquan W, Shaozhu L, Yuyan L, Qi Z and Huige W. Thermal stability, thermal decomposition and mechanism analysis of cycloaliphatic epoxy/4,4'-dihydroxydiphenylsulfone/ aluminum complexes latent resin systems. Journal of Wuhan University of Technology - Materials Science Edition. 2012; 27:1061-1067. http://dx.doi.org/10.1007/ s11595-012-0601-5 